\title{
INVISIBLE COHABITANTS
}

\author{
Investigating the Microbial Presence in \\ the Kitchen Sponges of Maastricht
}

Sara Jovanovska, Lucy Quirant, Davor Davidovikj \& Herman E. Popeijus

Abstract This study examines the correlation between the presence of bacteria in kitchen sponges of Maastricht students and the number of sponge users. Participants from 34 households were given a new kitchen sponge that they used for seven days. The samples were examined by performing a standard plate count on blood agar plates to approximate the number of colonies present on each sponge. Linear regression was performed using a 5\% statistical significance. The number of bacteria per sponge was on average the same, indicating that the number of bacteria associated per person is smaller in larger households. Statistically significant correlations were observed between the amount of bacteria and variables such as dietary preference and gender. 


\section{Introduction}

The sponge as a cleaning device is present in nearly every household for various purposes, ranging from disinfecting bathrooms to cleaning kitchen equipment. Kitchen sponges - in particular because of their ability to get rid of food residues - are utilized on a day-to-day basis during kitchen cleaning. Consequently, it is inevitable for a large portion of food remnants to be absorbed by the sponge, resulting in a suitable environment for the growth of various types of bacteria (Alwakeel, 2007). Numerous studies have investigated the bacterial presence in kitchen sponges. To illustrate, a study that aimed to identify the most contaminated household objects discovered that the highest microbial concentration was found in the kitchen, with the sponge exhibiting the highest level of contagion (Donofrio et al., 2012). Moreover, studies have shown that such microorganisms tend to survive in sponges for weeks after initial contact (Kusumaningrum, van Putten, Rombouts, \& Beumer, 2002). Lastly, even though most of the bacteria present in kitchen sponges are harmless, various studies have cited sponges as carriers of potential pathogenic bacteria such as Escherichia coli (E. coli) and Salmonella (Alwakeel, 2007; Josephson, Rubino, \& Pepper, 1997; Scott, Bloomfield, \& Barlow, 1982).

Despite the extensive research done on the presence of bacteria in kitchen sponges, there are some evident gaps in information. Firstly, few such studies have put their focus on student houses, which are particularly vulnerable to high levels of microbial contamination. A study done in Maastricht reports that dishcloths in student houses contain on average 7.9 billion bacteria, compared to only 3.1 million in the average Dutch household (Lübbert, 2013). Furthermore, a significant portion of such studies have been done in controlled environments through artificially contaminating sponges, rather than through sponge collection from households (Kusumaningrum et al., 2002). Although the former method is particularly useful for investigating the actual strain, growth and longevity of bacteria in kitchen sponges, the latter provides a more realistic and natural picture of the examined environment's hygiene. Thirdly, students typically live in shared accommodation and often share a kitchen sponge, but no studies have researched into how bacterial presence correlates with the amount of sponge users, that is, the number of housemates sharing a sponge. Several studies have assessed how an increase in the number of users of a particular appliance may influence its overall hygiene; however, those studies have focused solely on sanitation facilities such as toilet seats (Günther et al., 2012; Simiyu, Swilling, Cairncross, \& Rheingans, 2017). Lastly, no studies have considered the heterogeneity of a household's inhabitants, and analyzed how the amount of 
sponge bacteria correlates with characteristics such as gender and dietary preferences of the participants.

Motivated by these gaps in research, this paper asks the following research question: How does the amount of bacteria in kitchen sponges of Maastricht student houses correlate with the number of sponge users? Furthermore, how does the amount of bacteria correlate with household features such as the gender and diet of the users? Based on previous findings, the study predicts a positive correlation between the amount of bacteria and number of sponge users. Because of a lack of previous research, a more exploratory approach is taken to tackle the second part of the question.

The study aims to shed light on multiple issues of social relevance. First and foremost, showing that kitchen sponges in student houses are indeed abundant with bacteria and represent a potential source for diseases may increase awareness amongst Maastricht students. This might in turn lead to positive effects on health and well-being, caused by a shift in mindset when it comes to students' cleaning habits. Secondly, finding a correlation between bacterial presence in kitchen sponges and certain household features may indicate that certain types of student households are more susceptible to poor kitchen hygiene and potentially food contamination. This may motivate institutions to place a stronger accent on introducing or improving public health policies when it comes to student houses. Lastly, an indication to certain correlations may prove inviting for other researchers to undertake similar, yet more comprehensive studies regarding this issue.

\section{Relevant theory}

Previous research has focused on diverse issues concerning the presence of bacteria in sponges. It has been shown that pathogens contaminate sponges and remain after washing up. Mattick et al. (2003) found that not all bacteria is removed from the sponge during the washing up process. Moreover, although drying reduces the number of bacteria, the study found that E. Coli, and Salmonella, survived towel and air-drying for over 24 hours. Certain sterile dishes were also infected with E. Coli, Salmonella, and Campylobacter after being washed with infected sponges (Mattick et al., 2003). Another study confirmed that pathogens (such as Salmonella enteritidis and Staphylococcus aureaus) survive for days, and that food pathogens can be transferred from infected sponges and cloths in the wiping of surfaces (Alwakeel, 2007; Kusumaningrum, Riboldi, Hazeleger, \& Beumer, 2003). 
Testing in a laboratory and in a household can have very different effects, and cleaning products seemed to be much less effective on used sponges than on the new ones used in the laboratory setting (Kusumaningrum et al., 2002). The type of sponge needs to be standardized, as bacteria seem to grow better on rayon, cotton, and polyester sponges as opposed to pulp sponges. The type of material of sponges also affects how easily the bacteria can be removed (Lee, 2010). Very few studies tested the actual presence of these bacteria in sponges collected from households. One such study in Saudi Arabia found a high concentration of a range of bacteria that cause not only foodborne illness, but varying diseases, confirming the need to examine sponges in household settings (Alwakeel, 2007).

The literature on hygiene in regards to large groups is sparse but a few have been conducted on shared sanitation facilities. A study in the urban slums of Kampala on toilet hygiene found a clear and strong negative correlation between number of users and the cleanliness of a toilet stance (Günther et al., 2012). Another study in Kenya found an inverse relationship between sanitation quality and number of household users, indicating decreasing cleanliness with increasing number of users. Larger numbers of users make coordination and decision making more difficult, and this generally is accompanied by a lack of trust among users too (Simiyu et al., 2017). Various authors attempt to set a limit on the number of users ranging from sharing between two households (Kabange $\&$ Nkansah, 2015) to a maximum of four households (Günther et al., 2012). However, numbers alone are not enough. Other factors such as inhabitant distribution should also be considered when proposing recommendations (Simiyu et al., 2017).

\section{Methodology}

\section{I Sample distribution and survey collection}

The sponges collected in this study were all from students in Maastricht, in the Netherlands. A public announcement on social media was made looking for participants interested in a study that will be investigating the presence of microbes in kitchen sponges. Each respondent was provided with a new kitchen sponge by the research team. The sponge brand was standardized to avoid errors in the results due to variation in sponge size and material. Respondents were required to fill out a survey consisting of questions that describe their household characteristics.

\subsection{Sample collection}

Each sample was collected in an individual leak-proof, previously unused plastic bag. The time required for transportation was minimized between collection 
and testing, as the usability of the samples decreases substantially after 24 hours (Alexander \& Strete, 2001). The sponges were collected with minimal handling and placed separately inside the plastic bags which were labelled with all relevant information, including the date and time of collection. Once all samples were collected, they were transported to the laboratory at the Faculty of Health, Medicine and Life Sciences (FHML) in Randwyck.

\subsection{Part I of laboratory work: serial dilutions and testing}

Two precursory tests were performed on a used sponge that was not part of the experimental sample and a new sponge identical to the ones that would be distributed to participants. The aim was twofold: firstly, a serial dilution was performed to produce at least one countable plate that would serve as an indication of what concentration of bacteria should be plated to count the cell density of the sponge samples collected the following week. Secondly, it was also in the objective to determine that used sponges really do contain more bacteria than new ones.

Samples of $8 \mathrm{~cm}^{3}$ were aseptically cut from both sponges. The samples were taken by volume rather than by weight in order to minimize differences between wet and dry samples (wet sponges being much heavier than dry ones). The sample was placed in a tube with distilled water $(10 \mathrm{ml})$ and shaken for approximately 30 seconds, creating a very concentrated mixture containing an unknown density of bacterial cells. This original concentration must be diluted because plating a high concentration of bacteria would cause an uncountable amount of colonies on the plate, where the colonies are so overgrown and densely packed that they are indistinguishable from one another. After diluting the sample, a known volume of each dilution (the mixture of the bacteria-containing sample and the water) was spread onto blood agar plates composed of 5\% of sheep agar and incubated at $37^{\circ} \mathrm{C}$ for 24 hours, allowing bacterial colonies to grow, after which they were visually examined. It was observed that the plate containing the highest concentration of bacteria from the new sponge contained four colonies, which all originally developed from single cells, as depicted in figure 1A. The plates containing bacteria from the old sponge were uncountable, as too many colonies had formed, meaning that the concentration of the 40 collected samples would have to be further diluted to produce countable results (figure 1A).

\subsection{Part 2 of laboratory work: sponge testing and results}

Samples of $8 \mathrm{~cm}^{3}$ were measured using a ruler and cut out using scissors from the sponges. The ruler and scissors were sterilized between sponges. The samples were placed in tubes containing distilled water $(10 \mathrm{ml})$ and shaken for approx- 
imately 30 seconds using the vortex shaker in order to contaminate the water with the bacteria present in the sponge. Samples were then taken from the tubes using the appropriate pipette to make two dilutions: one solution of the original concentration diluted 1000 times, and one diluted 10000 times. Samples of $100 \mu \mathrm{l}$ were then taken from both concentrations and plated on blood agar plates, which were then stored at 37 degrees for 24 hours. In order to control for the cleanliness of the collection and sampling materials, a sample of the distilled water and of an unused plastic Ziploc bag were also diluted, plated and incubated. The following day the colonies present on the plates were examined. Only the plates containing liquid diluted 10000 times were counted as those containing liquid diluted 1000 times were, for the most part, overgrown, and therefore uncountable.

Each plate was divided into sections of four, eight or sixteen, depending on the apparent density of the colonies, and the colonies were counted manually. The number of colonies counted was then multiplied by the number of sections the plate had initially been divided in in order to get the total number of colonies present on each plate.

\subsection{Additional testing: chrome agar plates}

In addition to the plating and counting of bacteria, some additional tests were performed to gauge some tentative information about the types of bacteria present on the sponges. As identification of bacteria was not the primary aim of the research, the scientific underpinning of the experiments will not be explained at length. The research team came across several interesting findings, the most pertinent being that some of the bacteria present on the sponges came from human stool. Samples were taken at random from the already cultured bacteria and plated on a different, selective medium called Chromagar. The source of the dark bacterial strains, depicted in figure 1D, is human stool; their presence on the sponge can be explained either by improper hand washing, or by cross-contamination through flies. 
A)

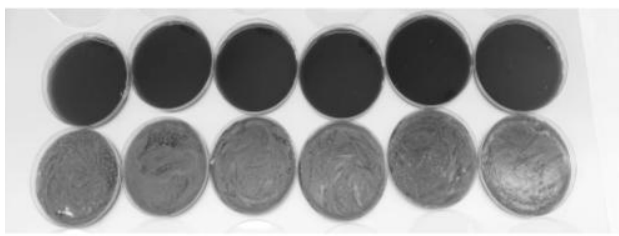

C)

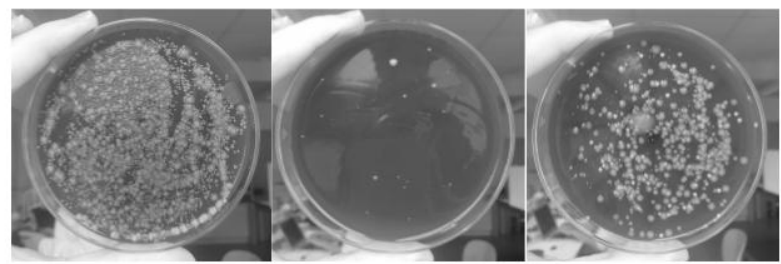

B)

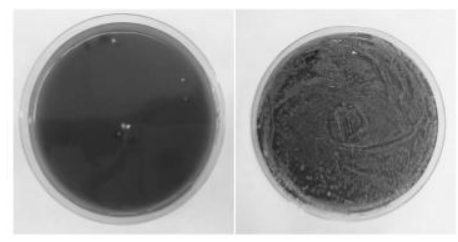

D)

Figure I A) Top row: results of serial dilutions performed on sample taken form new sponge. Bottom row: results from serial dilutions performed on sample taken from old sponge. B) Comparison of new sponge (left) and old sponge (right). C) Examples of the diversity of microbes found in samples taken from test sponges. D) Results from chrome agar plate.

\section{$4 \quad$ Analysis and discussion of results}

The results from the bacterial testing along with the survey responses were sorted and analysed using MATLAB. Linear regression was used to find the most suitable linear fit for each data plot. All results were tested using a 5\% statistical significance.

\section{I Number of Users}

No statistically significant relationship was found between the number of sponge users in a household and the number of bacteria in the sponge. The number of bacteria across all of the samples seems to be generally constant, independent of the number of users. The average number of bacteria contained in a $1 \mathrm{~cm}^{3}$ sponge sample amounted to around 150 colonies. Counterintuitively, the sponge with the highest amount of bacteria (around 300) was shared between only two people, while the one sponge shared by nine people only contained about 50 bacteria per $\mathrm{cm}^{3}$. This is equivalent to saying that the amount of bacteria 
that each person in a household would 'contribute' with will decrease with the increase in the number of sponge users. Figure 2A shows the number of users plotted against the number of bacteria per $\mathrm{cm}^{3}$ per person. A clear negative correlation ( $p=0.006)$ can be seen between the two variables. The usefulness of this graph is that it provides a different picture of the households' sponge hygiene by normalizing the scale to bacteria per person instead of total amount of bacteria.

Several reasons may be responsible for the fact that in smaller households each person is associated to more bacteria. On the one hand, the accumulation of bacteria in a sponge with increase in time and use might be logarithmic. In other words, there might be a physical explanation that there is a saturation point at which further accumulation of bacteria in the sponge is no longer possible. Another reason could be that more frequent use means more use of detergent, which in turn kills a large portion of the bacteria. Therefore, although more bacteria is absorbed by the sponge with each use, the use of detergent reduces the overall quantity of bacteria in the sponge.

On the other hand, an interpretation that highlights the social dynamics underlying sponge usage is that larger groups may be better at coordinating cleaning practices through implementation of stricter schedules and task delegation. This goes contrary to the arguments made by Günther et al. (2012) and Simiyu et al. (2017) who suggest a negative relationship between the number of users and the cleanliness of public sanitation facilities. The latter study suggests that one of the explanations for its observed relationship could be that a large number of users are more difficult to coordinate, making collective decision-making and implementation of rules harder to control (Simiyu et al., 2017). It seems that the same logic does not apply in the context of students sharing a kitchen sponge. This may hint to higher levels of community spirit and increased cohesiveness within student housing, which perhaps is a decisive for better coordination when it comes to chores. Moreover, the fact that a person is sharing a sponge with more people may induce a feeling of responsibility, but also peer pressure to maintain an optimal level of kitchen hygiene. In contrast, living alone might mean feeling less responsibility and external pressure to take care of kitchen cleaning equipment.

\subsection{Diet}

Plotting the percentage of vegetarians/vegans in a household against the total amount of bacteria in that household shows a strong correlation $(p=0.001)$ between the two variables, with fully vegetarian/vegan households having the least bacteria on average (figure 2B). Conversely, houses with no vegetarians/ vegans turn out to have the highest concentration of bacteria. Similarly, the household with the least bacteria in their sponge (around 10 per $\mathrm{cm}^{3}$ ) appears to be 
fully vegetarian/vegan, while the house with no vegetarians/vegans seems to have the most bacteria from the analysed samples (around 320 per $\mathrm{cm}^{3}$ ). Unfortunately, there is little literature concerning the disparities in bacterial presence between vegan/vegetarian and omnivore households. Possibly, the reason behind this relationship may be because fully vegetarian/vegan households cook meals that leave behind less bacteria, resulting in a more effective sponge cleaning process.

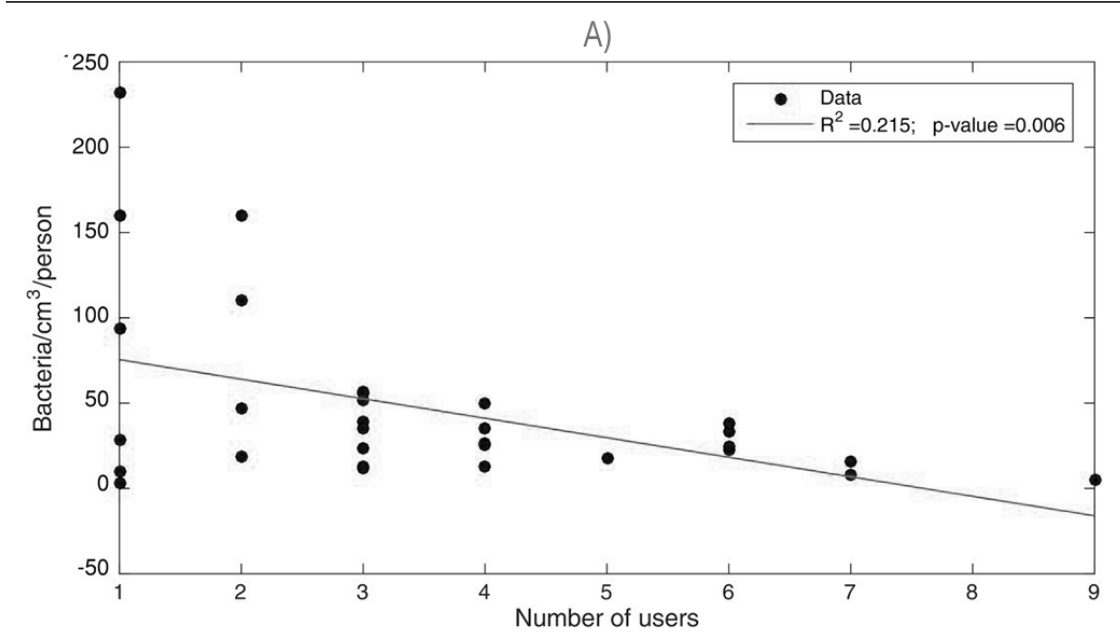

B)

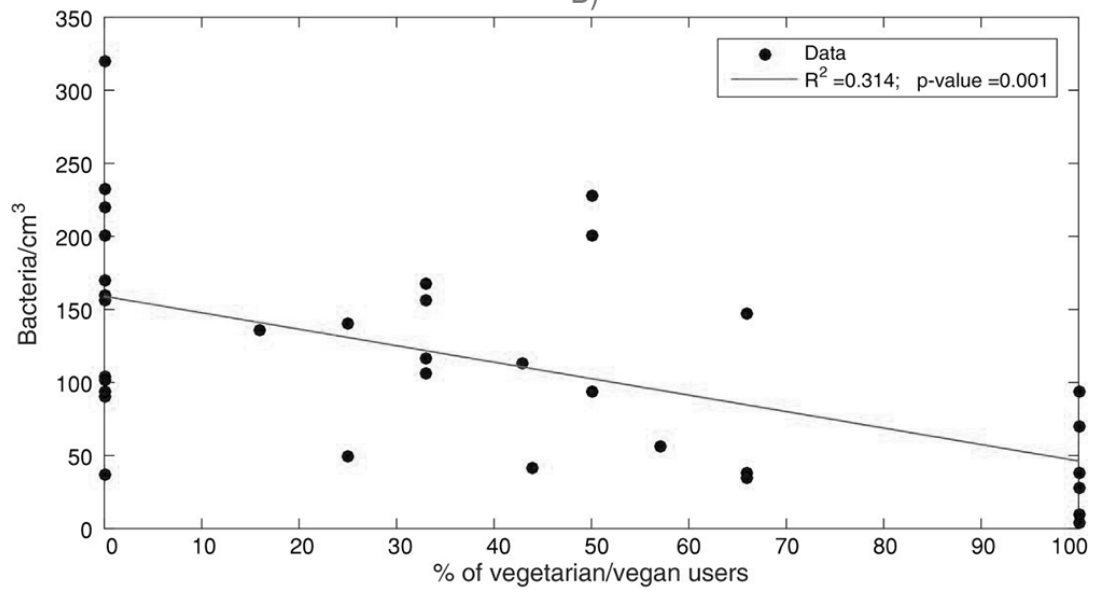

Figure 2 A) Number of users against amount bacteria per $\mathrm{cm}^{3}$ per person; B) Percentage of vegetarian/vegan users in a household and amount of bacteria per $\mathrm{cm}^{3}$ 


\subsection{Gender}

The correlation between female users and bacteria is significant at 5\% ( $\mathrm{p}=$ 0.001) (figure $3 \mathrm{~A}$ ). The figure indicates that the number of female sponge users in a household may significantly influence the cleanliness of the sponge. Considering the percentage of female sponge users only (figure 3B) explains the conclusions from the previous figure, indicating that fully female households have much less bacteria on average than fully male households. In other words, as the number of female sponge users in a household increases towards $100 \%$, the number of bacteria per $\mathrm{cm}^{3}$ per person decreases. Moreover, the bar chart (figure 12C) gives a further indication to the hygiene discrepancies between fully male and fully female households, showing that a male in a fully male household is responsible, on average, for around 150 bacteria per $\mathrm{cm}^{3}$, while an average female in a fully female household contributes with only around 30 bacteria per $\mathrm{cm}^{3}$. Mixed households shown similar characteristics to female households, with an average person yielding slightly more than 30 bacteria per $\mathrm{cm}^{3}$.

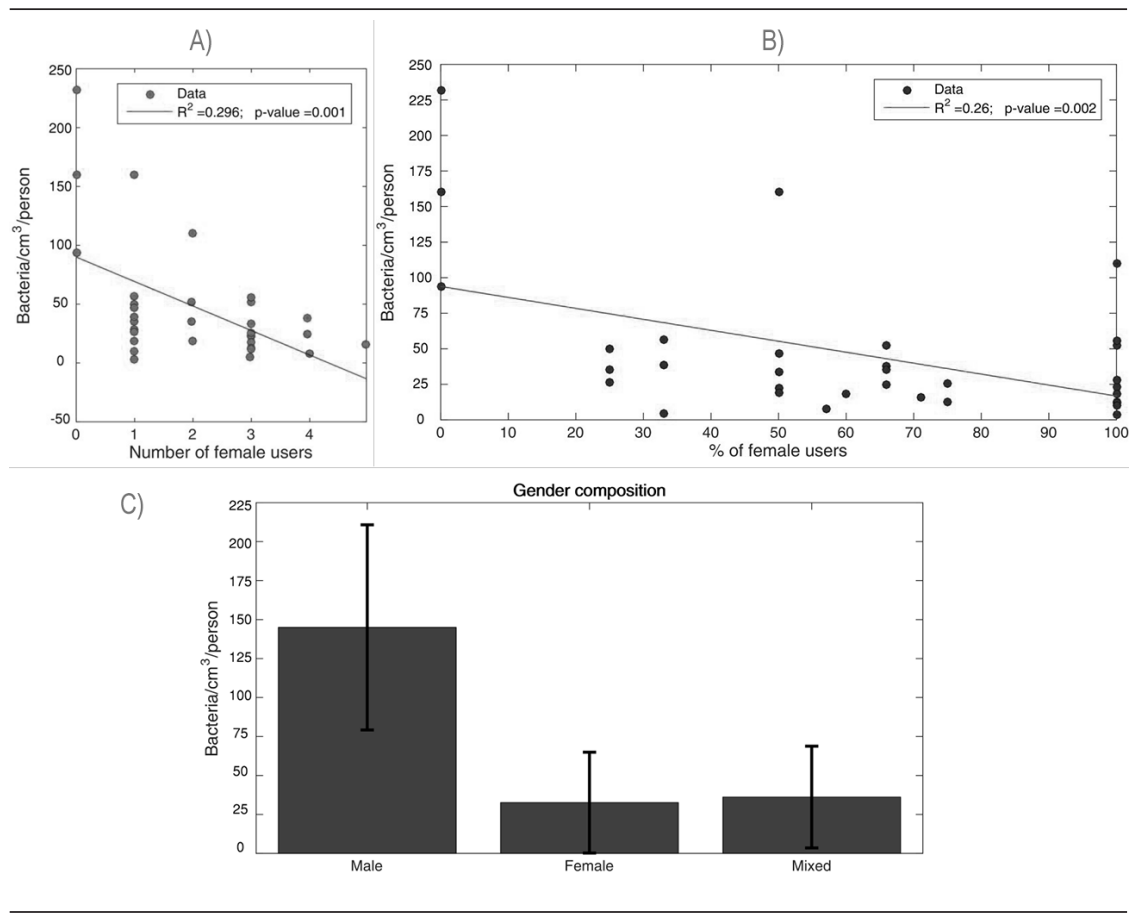

Figure 3 A) Number of female users and amount of bacteria per $\mathrm{cm}^{3}$ per person; B) Percentage of female users and amount of bacteria per $\mathrm{cm}^{3}$ per person; $C$ ) Differences between fully male, fully female and mixed households. 
Differences in hygiene habits between males and females have been a focal point for numerous studies. Many studies have shown that household chores are predominantly done by women (Starrels, 1994; Tai $\&$ Treas, 2013). Most of these studies are done about partnerships. Men often partake in significantly fewer chores and prefer grocery shopping and cooking over cleaning and laundry (Tai $\&$ Treas, 2013). Starrels (1994) found that husbands participate fully in only one fifth of household chores. It is interesting to highlight this known social fact that cleaning and household chores are associated with women. It should be noted that these studies focus on couples and families. The present study about sponges focused on young females living in student accommodations. The societal pressure of gender division is probably very different from a household setting.

A study by Clough (2011) shows that gender norms about cleanliness are installed in girls from a very young age in the industrialized North and West. Already at preschool, girls are taught and expected not to dirty their clothes. Parents often dress the girls in dresses and make them aware of the gender expectations of keeping those dresses clean, by for example not playing sports outside. Furthermore, among sufferers of Obsessive Compulsive Disorder, hand washing and cleaning compulsions appear far more frequently in women than men (Clough, 2011).

These studies confirm the observed gender hygiene patterns found which attribute a higher degree of cleanliness to female household inhabitants when it comes to bacteria in sponges. However, the difference in sample characteristics must be noted between this paper and the previously described survey, since the latter comprises solely of heterosexual, two-person households that may or may not be students. Other reasons hypothesized to explain the findings about gender in this study are that females may be better at collective decision making than males. Yet another reason may be connected back to the dietary preferences, as the percentage of vegetarians/vegans is larger in fully female households compared to fully male households.

\section{Conclusion and recommendations}

The study found no statistically significant correlation between the number of sponge users and bacteria in sponges. It was shown that in large households each person is 'responsible' for less bacteria than in smaller houses. This may be due to better teamwork and coordination of large households, coupled with more responsibility and peer pressure felt when living with more people as opposed to 
living alone. Another reason may have to do with kitchen sponges having a certain threshold of bacteria that they can absorb.

Lower amounts of bacteria were observed in fully female households in comparison to fully male households. Female inhabitants may be more coordinated when it comes to hygiene when they are living in a homogenous household. Specific gender roles may serve as another explanation, while the fact that the majority of the respondents with vegetarian/vegan diets were female may also be a factor.

A negative relationship was found between the percentage of vegetarian/vegan users in a household and the number of bacteria, showing that households with a larger portion of vegetarian/vegan users tend to have less bacteria in their kitchen sponge. A possible explanation for this trend may be the potentially less efficient cleaning of sponges used by omnivores (especially during the preparation of meat), since residues from certain foods could be harder to eliminate from the sponge.

Bearing everything in mind, this paper identified several risk groups: predominantly male households, non-vegetarian/vegan households, and established that each person is responsible for more bacteria in smaller households. The paper is an interesting read for epidemiologists (controlling of potential disease outbreaks), policy makers (especially policies regarding shared student households), and those in the field of education (introducing students to various sponge cleaning practices and dietary preferences). However, while risk groups have been identified, it is recommended to all to clean their sponges regularly. According to Sharma, Eastridge, and Mudd (2009) putting sponges in the microwave or dishwasher is significantly more effective than immersing them in a chemical treatment such as bleach, lemon juice or deionized water. Studies have also found that high doses of dishwasher liquid are effective at eliminating pathogens (Kusumaningrum et al., 2002).

All in all, a more extensive, observational study, encompassing a wider array of participants must be conducted in order to reach more robust conclusions regarding the relationship between these household characteristics and number of bacteria present in kitchen sponges in student houses. In particular, explaining the relationship found that each person is responsible for more bacteria in smaller households is of interest, and may benefit especially from interdisciplinary research that could more closely inspect the social dynamics of student households and how these affect kitchen cleaning practices. 


\section{Limitations}

Despite a number of significant findings, this study comes with some limitations. Firstly, in order to be able to draw statistically relevant conclusions, a larger sample size should be used. The sample size of 34 households led to an insufficient amount of responses to several questions in the survey for which strong conclusions could not be made. A second important limitation is the method used for the counting of the bacteria. The bacteria were grown on the agar plates and counted by hand, with each team member counting one third of the plates. Thus, not only is it expected for the method used to yield rough estimates of the actual results, but also a variation in counting styles from each team member is also expected to influence the correctness of the numbers. Often there was a high density of bacterial colonies, so the plate was divided into sections, such as four, eight, or sixteen sections. Counting was then done on one section, with the results of it being multiplied by the number of sections.

Furthermore, experimental errors may have occurred in the plating procedure. Examples include improper sterilization, or incorrect water amounts being pipetted for the dilution. Finally, the study relies on participants correctly filling out the survey and using the sponge regularly. There is undoubtedly a disparity in frequency of sponge use between participants, with some using it more often than others. Moreover, participants were not asked whether they own a dishwasher, which may have influenced the amount of time they used their sponge.

\section{References}

Alexander, S. K., \& Strete, D. (2001). Microbiology: A photographic atlas for the laboratory. San Francisco: Benjamin Cummings.

Alwakeel, S. S. (2007). Bacterial and Aspergillus spp. contamination of domestic kitchens in Riyadh, Saudi Arabia. Saudi Journal of Biological Sciences, 14(1), 1-6. Retrieved from http:// www.academia.edu/6942138/Bacterial_and_Aspergillus_spp._Contamination_of_Domestic_ Kitchens_in_Riyadh_Saudi_Arabia

Clough, S. (2011). Gender and the hygiene hypothesis. Social Science \& Medicine, 72(4), 486-93. doi:10.1016/j.socscimed.2010.11.021

Donofrio, R. S., Bechanko, R., Hitt, N., O’Malley, K., Charnauski, T., Bestervelt, L. L., Saha, R., \& Saha, N. (2012). Are we aware of microbial hotspots in our household? Journal of Environmental Health, 75(2), 12-9. Retrieved from https://www.nsf.org/newsroom_pdf/journal_of_envir_ health_sept_2012_microbial_hotspots.pdf 
Günther, I., Niwagaba, C. B., Lüthi, C., Horst, A., Mosler, H.-J., \& Tumwebaze, I. K. (2012). When is shared sanitation improved sanitation? The correlation between number of users and toilet hygiene. Munich Personal RePec Archive. doi: 10.13140/RG.2.2.10422.09288

Josephson, K., Rubino, J., \& Pepper, I. (1997). Characterization and quantification of bacterial pathogens and indicator organisms in household kitchens with and without the use of a disinfectant cleaner. Journal of Applied Microbiology, 83(6), 737-750. doi: http://dx.doi.org/10.1046/ j.1365-2672.1997.00308.x

Kabange, R.S., \& Nkansah, A. (2015). Shared sanitation facilities: A reality or mirage? American Scientific Research Journal for Engineering, Technology, and Sciences, 14(1), 172-177. Retrieved from http://asrjetsjournal.org/index.php/American_Scientific_Journal/article/view/936/579

Kusumaningrum, H. D., van Putten, M. M., Rombouts, F. M., \& Beumer, R. R. (2002). Effects of antibacterial dishwashing liquid on foodborne pathogens and competitive microorganisms in kitchen sponges. Journal of Food Protection, 65(1), 61-65. Retrieved from https://www.ncbi.nlm. nih.gov/pubmed/11811157

Kusumaningrum, H. D., Riboldi, G., Hazeleger, W. C., \& Beumer, R. R. (2003). Survival of foodborne pathogens on stainless steel surfaces and cross-contamination to foods. International Journal of Food Microbiology, 85(3), 227-236. Retrieved from https://www-sciencedirect-com. ezproxy.ub.unimaas.nl/science/article/pii/S0168160502005408?_rdoc $=1$ \&_fmt $=$ high\&_origin $=$ gateway\&_docanchor $=\& m d 5=b 8429449 c c f c 9 c 30159$ a5f9aeaa92ffb \&ccp $=y$

Lee, S. Y. (2010). Survival and growth of Escherichia coli on various commercial dish sponge/dishcloths and inhibitory effect of UV sterilization with or without moderate heat. Journal of Food Safety, 30(3), 721-731. Retrieved from https://onlinelibrary.wiley.com/doi/full/10.1111/j.17454565.2010.00236.x

Lübbert, A. (2013, May 15). Student house holds 79 billion bacteria. Observant. Retrieved from: https://www.observantonline.nl/English/Home/Articles/articleType/ArticleView/articleId/1308/ categoryId/49/Student-house-holds-79-billion-bacteria

Mattick, K., Durham, K., Domingue, G., Jørgensen, F., Sen, M., Schaffner, D. W., \& Humphrey, T. (2003). The survival of foodborne pathogens during domestic washing-up and subsequent transfer onto washing-up sponges, kitchen surfaces and food. International Journal of Food Microbiology, 85(3), 213-226. Retrieved from https://www.sciencedirect.com/science/article/pii/ S016816050200510X

Scott, E., Bloomfield, S., \& Barlow, C. (1982). An investigation of microbial contamination in the home. Journal of Hygiene, 89(02), 279-293. doi:10.1017/s0022172400070819

Sharma, M., Eastridge, J., \& Mudd, C. (2009). Effective household disinfection methods of kitchen sponges. Food Control, 20(3), 310-313. Retrieved from https://www-sciencedirect-com.ezproxy. ub.unimaas.nl/science/link?ref_val_fmt=info:ofi/fmt:kev:mtx:journal\&svc_val_fmt=info:ofi/ fmt:kev:mtx:sch_srv\&rfr_dat=saltver:1\&rfr_dat=origin:ONECATE\&ctx_enc $=$ info:ofi/ enc:UTF-8\&ctx_ver=Z39.88-2004\&rft.issn $=09567135 \& r f t$.volume $=20 \& r f t$.spage $=310 \& r f r$ dat $=$ md5:953555340097b6556510340860d5d9db 
Simiyu, S., Swilling, M., Cairncross, S., \& Rheingans, R. (2017). Determinants of quality of shared sanitation facilities in informal settlements: case study of Kisumu, Kenya. BMC Public Health,17(1). doi:10.1186/s12889-016-4009-6

Starrels, M. (1994). Husbands' involvement in female gender-typed household chores. Sex Roles: A Journal of Research, 31(7-8), 473-491. doi:10.1007/BF01544202

Tai, T., \& Treas, J. (2013). Housework task hierarchies in 32 countries. European Sociological Review, 29(4), 780-791. doi:10.1093/esr/jcs057 